\title{
Effect of frequency, temperature, and time of sonication on xanton content of mangosteen (Garcinia mangostana L.) peel extract through ultrasound assisted extraction
}

\author{
Suryono Suryono ${ }^{1, *}$, Hadiyanto Hadiyanto ${ }^{2}$, Moh. Yasin ${ }^{3}$, Retno Widyowati ${ }^{4}$, Muflihatul Muniroh ${ }^{5}$, and Annisa ${ }^{`}$ Amalia ${ }^{6}$ \\ ${ }^{1}$ Department of Physics, Diponegoro University, Semarang, Indonesia \\ ${ }^{2}$ Department of Chemical Engineering, Universitas Diponegoro, Semarang, Indonesia \\ ${ }^{3}$ Department of Physics, Faculty of Science and Technology, Airlangga University, Surabaya, (60115) Indonesia \\ ${ }^{4}$ Department of Pharmacognosy and Phytochemistry, Faculty of Pharmacy, Universitas Airlangga, Surabaya, Indonesia \\ ${ }^{5}$ Department of Department of Physiology, Faculty of Medicine, Diponegoro University, Semarang, Indonesia \\ ${ }^{6}$ Magister of Physics, Department of Physics, Faculty of Science and Mathematics, Diponegoro University, Semarang, Indonesia
}

\begin{abstract}
Ultrasound Assisted Extraction (UAE) has been used for the extraction of mangosteen peel (Garcinia mangostana L.) in producing xanton. Mangosteen peel extraction with UAE has been carried out to determine the effect of frequency, temperature, and time of sonication on the xanton content. The parameters controlled are frequency $(20-40 \mathrm{kHz})$, temperature $(25-35 \mathrm{oC})$, and sonication time $(20-40$ minutes). The solvent used in the extraction was methanol with a ratio of mangosteen peel: solvent $=1: 10$ and analysis of xanton content in the extraction. Extraction results showed that the content of xanthones from the extraction results of mangosteen (Gracinia mangostana L.) peel with UAE had optimum values at a frequency of $40 \mathrm{kHz}$, temperature of $35 \mathrm{oC}$, and sonication time of 30 minutes. At the same frequency, temperature, and time, conventionally showed xanthones content of mangosteen rind extract of $93 \mathrm{ppm}$. The results show that the extraction yield using UAE is greater than that of conventional methods. From the results of this experiment, it can be concluded that the use of the UAE in the xanthones extraction process of mangosteen peel (Gracinia mangostana L.) is more optimal when compared to conventional methods.
\end{abstract}

Keywords: Ultrasound assisted extraction; extraction; mangosteen; sonification; xanton

\section{Introduction}

Mangosteen (Garcinia mangostana L.) is a tropical plant that is spread in Asia. One of the substances contained in the mangosteen plant is xanton, which is used as an anticancer, antibacterial, and antifungal [1]. In addition, several studies have suggested that xanthones on mangosteen plants can also be used as a treatment for skin infections, dysentery drugs, stomachaches, anti$\mathrm{HIV}$, antihistamines, and antineoplastic [2]. Xanton is a very strong antioxidant compound in mangosteen also known to be able to withstand high polysaccharides naturally [3], so mangosteen can be used as a natural remedy for diabetes mellitus. Xanton can repair damaged pancreatic cells so that they are able to produce insulin optimally and increase the sensitivity of muscle cells to insulin in type 2 diabetes [4]. One of the contents of xanton substances that have strong antioxidant activity is the $\alpha$-mangostin compound whose extract form can be administered orally because xanton bioactive components are conjugated freely and are not conjugated with other compounds $[5,6]$.

The way to obtain the substances contained by using the extraction method. Conventional extraction methods that have been carried out include soxhlet extraction and Conventional Solvent Extraction. Both of these conventional methods require heating for a long time so that it causes a decrease in the function of the substance content $[7,8]$. At present, the extraction of the mangosteen fruit is still carried out conventionally so that it can eliminate some important substances because of the oxidation, ionization, and hydrolysis processes during the extraction process [9]. In addition to conventional methods, the extraction method that is often used lately is through Ultrasound Assisted Extraction (UAE). Technology development in the extraction process aims to shorten production time, save energy, and improve product quality [9]. Ultrasonic waves can accelerate chemical processes through acoustic cavities in materials by propagating wave pressure through liquids [10]. This makes the process of extracting a material shorter and reduce the chemicals used, and can maintain the quality of food ingredients and improve food function [11].

Factors that influence the extraction results include the type of solvent, solvent concentration, $\mathrm{pH}$, temperature, and extraction time. The optimum conditions for each of these factors depend on the

\footnotetext{
* Corresponding author: suryono@fisika.undip.ac.id
} 
method of extraction and the extracted material. Based on previous research, there has been no extraction with UAE in mangosteen (Garcinia mangostana L.) with variations in temperature, frequency, and time of extraction. Therefore, this study controls these three variables through extraction with UAE as a quick and simple extraction step in looking at the impact of each variable to obtain xanton compounds from mangosteen peel extract (Garcinia mangostana L.). Ultrasonic waves have been known to be generated electronically and have interactions with objects in their path [12].

\section{Material and Methods}

In Ultrasound Assisted Extraction (UAE), ultrasonic waves are generated by ultrasonic transducers made from piezoelectric materials that convert mechanical energy into electrical energy and vice versa [13]. The extraction process is carried out by shooting ultrasonic waves in the extracted material, causing the cavitation phenomenon in its molecules [14]. Figure 1 shows a diagram of the extraction system using the developed UAE. The extraction device used consists of software and hardware. The hardware is a piezoelectric transducer, a temperature sensor, and a microcontroller. The software is a data acquisition program that reads data from sensors sent by the microcontroller, then is displayed on a computer through a computer program. Monitoring is carried out in order to know the frequency, temperature, and time parameters when mangosteen fruit extraction takes place.

Mangosteen (Garcinia mangostana L.) rind to be extracted must be in fresh condition. Mangosteen rind powder is mixed with a solvent with a ratio between the mangosteen rind to be extracted and a solvent that is $1: 10$ [15]. Next, the solution is put into an extraction tube for sonication. During the ultrasonic power firing process, variations in frequency, temperature, and sonication time were carried out, respectively 20-40 $\mathrm{kHz}, 25-35{ }^{\circ} \mathrm{C}$, and 5-15 minutes. The solvent used is methanol. Extraction results were analyzed to find the xanthones content of the sample using the xanton standard with IR spectroscopy [1]. The analysis was done by looking at the xanton content of each treatment.

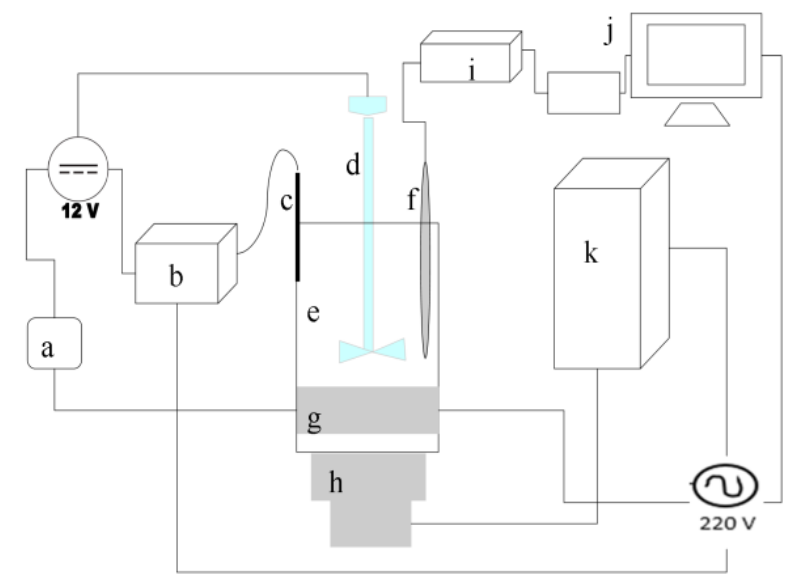

Fig. 1. Experimental set up of extraction system using UAE. a: relay, b: thermo controller, c: thermocouple, d: mixer, e: tank, f: thermal sensor, g: heater, h: transducers, i: microcontroller, $\mathrm{j}$ : mini PC, k: power ultrasound.

\section{Results and Discussion}

Testing on all components of the Ultrasound Assisted Extraction (UAE) device is carried out before starting the extraction including the characterization of the sensor used and calibration. Extraction is done when all components work well. The main objective of this study was to identify the xanton condition of mangosteen (Gracinia mangostana L.) peel extraction results with UAE by administering several variations of frequency, temperature, and time of sonication. Mangosteen rind powder sample was dissolved in a solvent in the ratio of $1: 10$. In previous studies mentioned the xanton content contained in mangosteen peel includes $\alpha$-mangostin (1), $\beta$-mangostin (2), and $\gamma$-mangostin (3) [2].

The results of the comparison of extraction xanton content with UAE include xanton compound content by IR spectroscopy analysis and identifying the effect of variations in frequency, temperature, and time of extraction. The results of xanton content of mangosteen peel extract from each variation of frequency, temperature, and sonication time are shown in Figure 2.

Analysis of the effect of sonication frequency on xanton content was carried out in the range of 30-40 $\mathrm{kHz}$. In Figure 2 it appears that some combinations show the xanton content increases dramatically from the frequency of $35 \mathrm{kHz}$ to $40 \mathrm{kHz}$. From this information, it can be stated that there is a significant change in the xanton content after the frequency of $35 \mathrm{kHz}$. Based on the data, the combination of temperature and time is fixed, showing that the xanton content is highest at a frequency of $40 \mathrm{kHz}$.

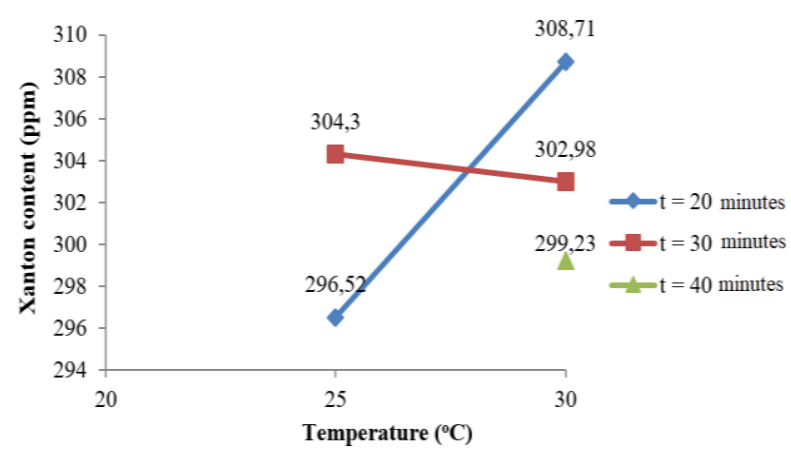

(a)

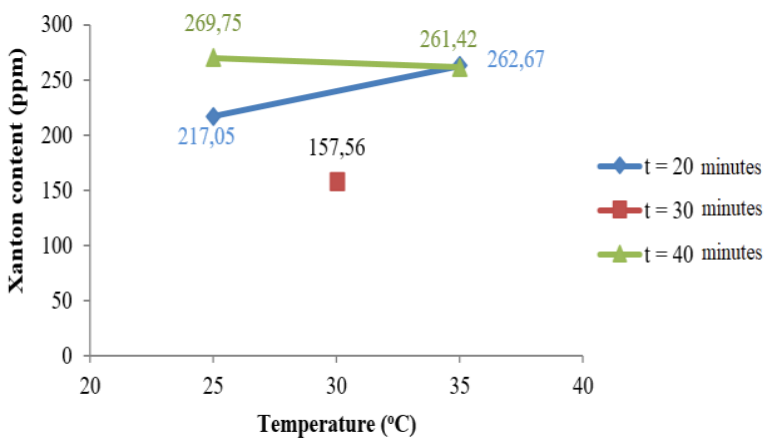

(b) 


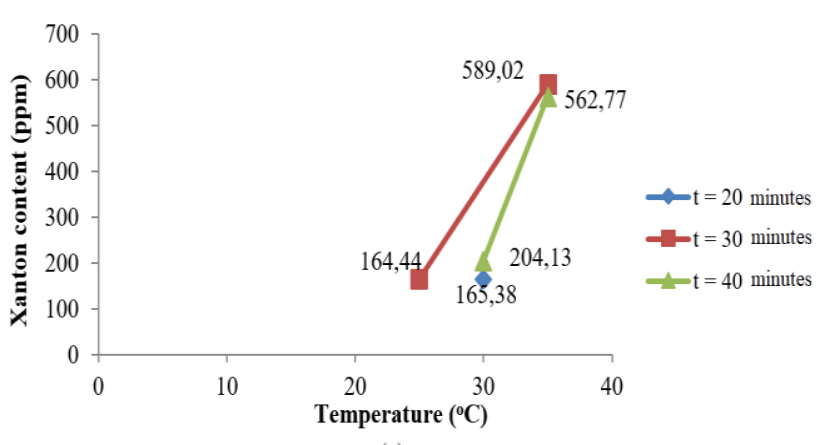

(c)

Fig. 2. Effect of temperature on xanton content of mangosteen peel extract with fixed sonication frequency and time: (a) $\mathrm{f}=$ $30 \mathrm{kHz}$, (b) $\mathrm{f}=35 \mathrm{kHz}$, (c) $\mathrm{f}=40 \mathrm{kHz}$

Ultrasonic frequency in extraction accelerates mass transfer from the solvent to the extracted substance [15]. When the frequency is increased beyond the required frequency it can cause bubbles to collapse in the sample so that the high frequency cannot extract all the target compounds. Frequency selection is done depending on the compound to be extracted [15]. Analysis of the effect of temperature on xanton content was carried out in the range of $25-35{ }^{\circ} \mathrm{C}$. In Figure 2 it appears that some combinations show the xanton content increases dramatically from $30 \mathrm{oC}$ to $35{ }^{\circ} \mathrm{C}$. From this information, it can be stated that there is a significant change in the content of phenolic compounds after 30 ${ }^{\circ} \mathrm{C}$. Based on the data, it shows that the xanton content is highest at $35{ }^{\circ} \mathrm{C}$. Increasing the temperature can increase the mass transfer process and increase internal energy. Increased temperature also causes cavitation bubbles in the liquid to increase so that it can produce xanton compounds more easily [9].

From the 15 variations that have been done, the results of the analysis show that the optimum content of xanthone extracted from mangosteen rind when done with a frequency of $40 \mathrm{kHz}$, temperature of $35^{\circ} \mathrm{C}$, and sonication time of 30 minutes. Then, at the same frequency, temperature, and time but the extraction done conventionally showed the results of the xanton content of mangosteen rind extract namely $93 \mathrm{ppm}$. The results showed that extraction using UAE was more effective than conventional.

Extraction using the UAE is more effectively carried out on materials that have a fine cell structure. In addition, the use of solvents with low concentrations and low temperatures can also make the extraction process effective with UAE [15]. Based on the results showed that the superiority of extraction with UAE compared to conventional methods is to produce more xanton substances. In addition, the use of low temperatures in extraction with UAE does not damage the constituent cells of the extracted material. Furthermore, differences in the composition of the extracted material also affect the extraction yield, so the selection of the right extraction method is needed so that the optimum conditions of extraction results can be obtained maximally [15].

\section{Conclusion}

The content of xanthones from the extraction results of mangosteen peel (Gracinia mangostana L.) with the optimum UAE at a frequency of $40 \mathrm{kHz}$, temperature of $35^{\circ} \mathrm{C}$, and sonication time of 30 minutes. namely mangosteen of $93 \mathrm{ppm}$. The results show that the extraction results using the UAE are greater than conventional methods. So, it can be concluded that the use of UAE in the xanthones extraction process of mangosteen peel (Gracinia mangostana L.) is more appropriate than conventional methods.

We acknowledge the directorate general of higher education of Indonesia who have provided funding for this research through the Konsursium Riset Perguruan Tinggi 2019 research project.

\section{References}

1. Y. Zhang, C. Liu, Y. Qi, Y. Li, S. Li, Separation and Purification Technology 144, (2015)

2. D. Kao, J.M. Henkin, D.D. Soejarto, A.D. Kinghorn, N.H. Oberlies, Phytochemistry Letters 28, (2018)

3. P. Karthiga, Biotechnology Research and Inovation 2 , (2018)

4. S. A. Husen, D. Winarni, F. Khaleyla, S. H. Kalqutny, A. N. M. Ansori, AIP Conference Proceedings 1888, (2017)

5. S.Tjahjani, W. Widowati, K. Khiong, A. Suhendra, R. Tjokropranoto, Procedia Chemistry 12, (2014)

6. A. Jariyapongskul, C. Areebambud, S. Suksamrarn, C. Mekseepralard, (2015), BioMed Research, (2015)

7. C. Faggio, A. Sureda, S. Morabito, A.S. Silva, A. Mocan, S.F. Nabavi, S.M. Nabavi, Eur. J. Pharmacol 04, (2017)

8. C.W. Liu, Y.C. Wang, H.C. Lu, W.D. Chiang 2014 Process Biochem 49, (2014)

9. F. Kong, S. Yu, Z. Feng, X. Wu, Pharmacogn. Mag. 11, 43 (2015)

10. H. Li, B. Chen, S. Yao, Ultrason. Sonochem 12, (2005)

11. A.C. Soria, M. Villamiel, Trends Food Sci.Techno. 21, (2010)

12. H.W. Pradhana, S. Suryono, A. Widodo, TELKOMNIKA 12, 2 (2014)

13. Junior A, dosSantos A.A, Ultrasonic Waves (Croatia: InTech), (2012)

14. K. Ameer, S.W. Bae, Y. Jo, H.G. Lee, A. Ameer, J.H. Kwon, J. Foodchem 01, (2017)

15. W. Wang, J. Jooyeoun, T. Elizabeth, Z. Yanyun, LWT Food Science and Technology 72, (2016) 